Article

\title{
Optimizing the Grouting Design for Groundwater Inrush Control in Completely Weathered Granite Tunnel: An Experimental and Field Investigation
}

\author{
Weihua Zheng ${ }^{1}$, Dengwu Wang ${ }^{2}$, Guijin $\mathrm{Li}^{1,3}$, Lin Qin ${ }^{4}$, Kai Luo ${ }^{2}$ and Jinquan Liu ${ }^{3,5, *}$ \\ 1 Jiangxi Vocational and Technical College of Communication, Nanchang 330000, China \\ 2 Jiangxi Road and Port Engineering Bureau, Nanchang 330000, Jiangxi, China \\ 3 Quanzhou Institute of Equipment Manufacturing, Haixi Institutes, Chinese Academy of Sciences, \\ Quanzhou 362000, China \\ 4 Guangxi Computing Center Co., Ltd., Nanning 530022, China \\ 5 Department of Civil and Environmental Engineering, Faculty of Science and Technology, \\ University of Macau, Macao 999078, China \\ * Correspondence: jinquan.liu@fjirsm.ac.cn
}

Received: 15 April 2019; Accepted: 18 June 2019; Published: 2 July 2019

\begin{abstract}
Groundwater and mud inrush disaster from completely weathered granite presents a huge difficulty for tunnel construction, which requires the grouting measurement with favorable performance. To propose the optimal material parameters for grouting, numerous tests, including strength, permeability, and anti-washout, were conducted to evaluate the effects of grouting filling ratio (GFR), curing age and water velocity on the grouting effect. The test results show that: (1) The hydraulic property of completely weathered granite can be significantly improved by increasing the grouting volume and curing age. In particular, when GFR $\geq 48 \%$, the cohesion and internal friction angle increased to about $200 \mathrm{kPa}$ and $30^{\circ}$, which were more than three and ten times of that pre-grouting. (2) With the increase of GFR, the permeability exhibited three stages: Slowly decreasing stage, sharply decreasing stage and stable stage. When increased from $32 \%$ to $48 \%$, the permeability coefficient sharply decreased two orders of magnitude, namely from $4.05 \times 10^{-5} \mathrm{~cm} / \mathrm{s}$ to $1 \times 10^{-7} \mathrm{~cm} / \mathrm{s}$. (3) The particle erosion rate decreased sharply to below $10 \%$ in the low water velocity $(v \leq 0.2 \mathrm{~m} / \mathrm{s})$ when GFR $\geq 48 \%$, but still exceeded $50 \%$ when $v \geq 0.4 \mathrm{~m} / \mathrm{s}$. The results indicated that the grouting volume of GFR $=48 \%$ was a suitable grouting parameter to reinforce the completely weathered granite, particularly in the low water velocity condition. The field investigation of hydraulic-mechanical behaviors in the Junchang tunnel indicated that the grouting effect can be improved markedly.
\end{abstract}

Keywords: groundwater control; completely weathered granite; tunnel engineering; grouting design; grouting reinforcement effect

\section{Introduction}

Tunnel constructing in completely weathered granite often faces the serious risk of groundwater and mud inrush [1-3], which presents a great difficulty for engineers. As the common treatment measure, grouting technology is far from the anticipated effect in rich-water conditions, especially in flowing water environments due to water erosion [4-7]. In this condition, the slurry is prone to be diluted and scoured, leading to the deterioration of water plugging and the ground reinforcement effect $[8,9]$. Therefore, the grouting design with the advanced performance of strength, permeability and anti-washout has become a key issue for the geotechnical engineers, which was strongly demanded in practical engineering $[10,11]$. 
The main factors of grouting design include material used, grouting control and grouting parameters $[12,13]$. The material used is the primary factor to prevent water and mud inrush disasters, which must be determined according to the hydrogeological conditions. In general, the favorable groutability of the used materials were desired in permeation grouting in order to penetrate the grout into the ground [13-15]. Furthermore, for the unfavorable geological environment, i.e., the dynamic water environment, the special slurry properties, i.e., the anti-dispersion properties, are crucial to the prevention of water inrush disasters [8]. Therefore, under rich-water completely weathered granite ground, the superfine cement cannot permeate into the ground due to its fine particle size, as demonstrated in Xiamen Xiang'an subsea tunnel [16] and Hong Kong's mass transit railway [17]. In addition, special grouts such as chemical grouts and polyurethane grouts possess potential advantages with anti-dispersion properties, which should be considered in dynamic water environments [11,18].

The grouting control main includes grouting pressure and grouting spread. In general, high grouting pressure can induce great grouting spread distance, but may also result in the damage to structures and the deformation of formation [19]. Therefore, a new method, namely grout intensity number (GIN), was developed to control grouting operation, which aimed to ensure that the high grouting pressure could inject the desired volume without damages to the structures [20]. However, this method was limited to use due to the difficulties in determining the grout spread and distinguishing the fractures state [21]. In order to obtain real- time control over the grouting spread, another new grouting control method was developed for permeation grouting by Still et al. [22,23], which had already been used in Swedish projects successfully. Nevertheless, in completely weathered granite ground, the grouting spread is dominated by fracture grouting, which is significantly different with permeation grouting, indicating that those methods were limited in completely weathered granite due to groutability.

Finally, the grouting parameters, particularly the grouting volume, are the foundation of the grouting design [24]. The conception of the grouting volume is to follow the method of filling ratio of porous by slurry from the permeation grouting. The previous designed methods to obtain the filling ratio were mainly relying on the experimental investigation of permeation grouting and the engineering experience $[25,26]$. In general, the higher filling ratio governs the better grouting reinforce effect. For sandy soil, Cui and Cui presented the filling ratio of $50-70 \%$ for medium and coarse sand, and $70-100 \%$ for gravel sand according to the permeation grouting theory [26]. Differently, the grouting filling ratio of $30-50 \%$ obtained from the field engineering was recommended for clay soil [26]. However, due to the difference of grouting mechanism in completely weathered granite and the special dynamic water environment, the above grouting volume may not fit for this formation and its appropriate grouting filling ratio should be studied in the future.

The objective of this study is to investigate the influence of grouting volume on the reinforcement effects in completely weathered granite in the rich-water environment and propose the appropriate grouting volume. First, a series of tests, including strength, permeability and anti-washout under different grouting filling ratios, curing ages and water flow rates, were conducted. Then the modifications of completely weathered granite at pre- and post-grouting were systematically analyzed and quantitatively evaluated. Accordingly, a referenced grouting volume was proposed from the experimental studies and was examined by the field test in Junchang tunnel in China.

\section{Materials and Design}

\subsection{Test Materials}

\subsubsection{Cement}

The rapid hardening sulphoaluminate cement used in this study (type R. SAC.42.5 in accordance with the standard GB20472-2006 of China) was from Huaxin Cement Plant Factory (Huangshi, P.R. China). According to the grouting ratio commonly used in grouting engineering, the water-cement 
ratio $(\mathrm{W} / \mathrm{C})$ of the grout was set as 0.8 . The initial setting time and compressive strength at $3 \mathrm{~d}$ of the cement were $21 \mathrm{~min}$ and $42.5 \mathrm{MPa}$ respectively.

\subsubsection{Completely Weathered Granite}

The completely weathered granite was taken from the Junchang Tunnel [13]. Tests by X-Ray Diffraction (XRD) analysis indicated that the minerals of the completely weathered granite were quartz particle, illite, and kaolinite with a mass proportion of $75.2 \%, 19.3 \%$, and $5.5 \%$, respectively. The basic physical and mechanical properties are shown in Table 1.

Table 1. Physical and mechanical properties of completely weathered granite.

\begin{tabular}{|c|c|c|c|c|c|c|c|}
\hline \multirow{2}{*}{$\begin{array}{l}\text { Natural Density } \\
\qquad\left(\mathrm{g} \cdot \mathrm{cm}^{-3}\right)\end{array}$} & \multirow{2}{*}{$\begin{array}{c}\text { Natural } \\
\text { Moisture (\%) }\end{array}$} & \multirow{2}{*}{$\begin{array}{l}\text { Cohesion } \\
c_{\text {uu }}(\mathrm{kPa})\end{array}$} & \multirow{2}{*}{$\begin{array}{l}\text { Internal Friction } \\
\text { Angle } \Phi_{\text {uu }}\left({ }^{\circ}\right)\end{array}$} & \multicolumn{4}{|c|}{ Proportion of Different Particle Size Groups/\% } \\
\hline & & & & $<0.0075 \mathrm{~mm}$ & $0.0075 \mathrm{~mm}-2 \mathrm{~mm}$ & $2-10 \mathrm{~mm}$ & $>10 \mathrm{~mm}$ \\
\hline 1.9 & 17 & 60.2 & 1.9 & 30.8 & 57.0 & 10.86 & 1.34 \\
\hline
\end{tabular}

\subsubsection{The grouting Sample of Completely Weathered Granite}

The grouting filling ratio (GFR) is a key index to design the grouting volume, which is defined as follows:

$$
G F R=\frac{Q}{V n(1+\beta)}
$$

where $Q$ is the grouting volume, $V$ is the volume of grouting ground, $n$ is the soil porosity which was 0.36 in the test, $\beta$ is the grouting loss rate which was $10 \%$ in the test according to the experience.

In the test, grouting filling ratios with $0 \%, 16 \%, 32 \%, 48 \%, 64 \%, 80 \%$ were designed to evaluate the influence of grouting volume on the grouting effect.

For the strength and permeability tests, the grouting samples were prepared by mixing the grout with the designed GFR into the completely weathered granite, according to the standard JGJ/T 233-2011 of China. Afterwards, the materials were mixed uniformity. The cylinder specimens for triaxial test and permeability tests were made with a size of $\Phi 39.1 \mathrm{~mm} \times 80 \mathrm{~mm}$ (diameter $\times$ height) and $\Phi$ $61.8 \mathrm{~mm} \times 40 \mathrm{~mm}$. For the anti-washout test, specimens with a cubic size of $40 \times 40 \times 40 \mathrm{~mm}^{3}$ were prepared by a self-developed grouting test device [27], as shown in Figure 1. The specimens were cured under standard conditions $\left(20^{\circ} \mathrm{C} \pm 2, \mathrm{RH}>90 \%\right)$ for designated ages of $3 \mathrm{~d}, 7 \mathrm{~d}$ before testing.

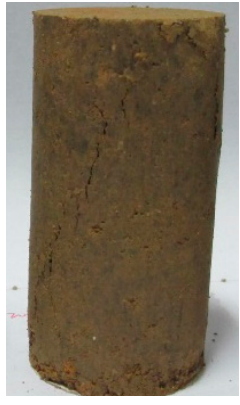

(a)

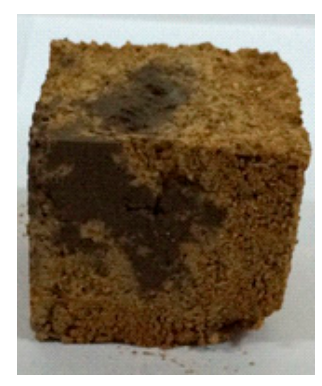

(b)

Figure 1. Test specimens for strength and anti-washout tests. (a) Cylinder specimen for the strength test; (b) cubic specimen for the anti-washout test.

\subsection{Test Procedure and Scheme}

\subsubsection{Strength Test}

Using the triaxial shear test, the strength characteristics of completely weathered granite preand post-grouting were investigated by the undrained unconsolidated triaxial method. The confining pressure was $200 \mathrm{kPa}, 400 \mathrm{kPa}, 600 \mathrm{kPa}$ and $800 \mathrm{kPa}$, respectively, in general, but it was changed to 
$100 \mathrm{kPa}, 200 \mathrm{kPa}, 300 \mathrm{kPa}, 400 \mathrm{kPa}$ for the sample with the high grouting fill ratio ( $\geq 48 \%$ ) considering the sample strength was relatively high.

\subsubsection{Permeability Test}

The variable head permeability test method was used to determine the permeability coefficient of the sample after grouting.

\subsubsection{Anti-Washout Test}

In order to evaluate the anti-washout properties of grouting samples, a self-design testing device was developed, which is shown in Figure 2 [27]. The device consisted of a sink, flow valve, water tank, and particles collection equipment. The length, width, and height of the sink were 200, 10, and $10 \mathrm{~cm}$, respectively. The flow valve was designed to adjust the water flow velocity. Three water velocities, including $0.2,0.4,0.6 \mathrm{~m} / \mathrm{s}$, were designed in the anti-washout tests.

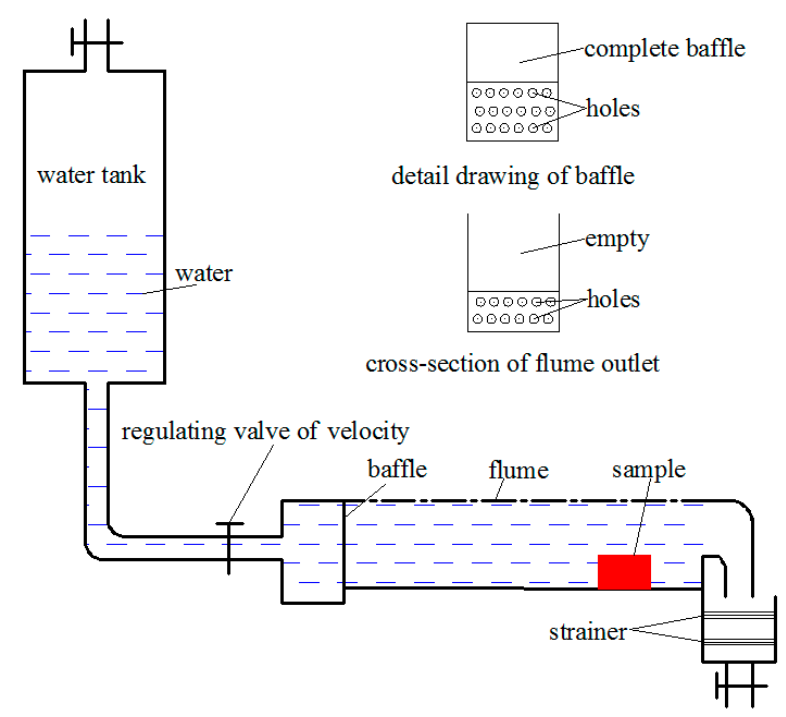

Figure 2. Anti-washout test device.

The detail anti-washout test procedure was illustrated as follows. First, the initial grouting sample with mass $M_{0}$ was placed into the sink under the designed water velocity. Then, the particle erosion amount was recorded at $10 \mathrm{~s}, 30 \mathrm{~s}, 60 \mathrm{~s}, 90 \mathrm{~s}, 120 \mathrm{~s}$ and following an interval of $60 \mathrm{~s}$. When the particle erosion amount between two records was less than $0.1 \mathrm{~g}$, namely, the particles were not eroded, the water inlet was closed. The total particle erosion amount can be collected from the collection system and the eroded mass $M_{1}$ was recorded. Thus, the anti-washout properties can be evaluated by the index of PER (particle erosion ratio), which is defined by the ratio of $M_{1} / M_{0}$.

\section{Test Results and Analysis}

\subsection{Strength Test}

\subsubsection{Stress-Strain Characteristics}

Figure 3 shows the stress-strain curves with different GFRs at a $7 \mathrm{~d}$ curing time. With an increasing GFR, the peak strength increased. In addition, the pattern of stress-strain curve changed with the increasing GFR. When the GFR was smaller than $48 \%$, as shown in Figure 3a,b, the sample exhibited the pattern of strain hardening. However, when the GFR was higher than $48 \%$, the stress-strain curve was gradually transformed into the pattern of strain softening, as shown in Figure 3c-e. This indicates that the failure model of completely weathered granite after grouting changed from plastic to brittle properties, and the strain localization occurred in the failure process under the action of shear stress. 


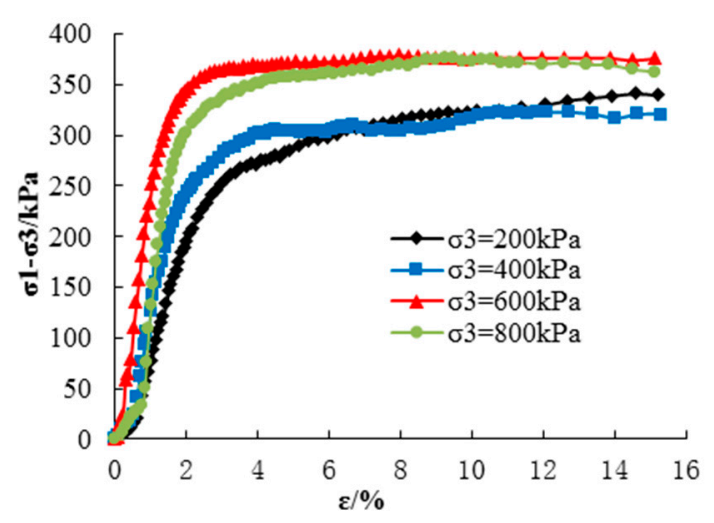

(a) $G F R=16 \%$

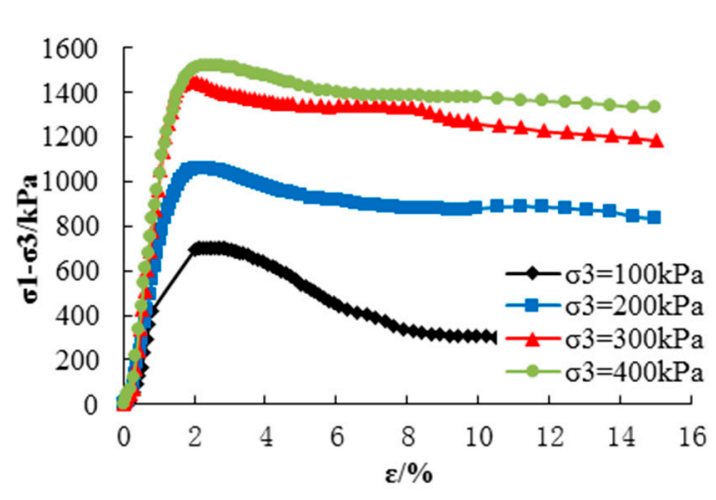

(c) $G F R=48 \%$

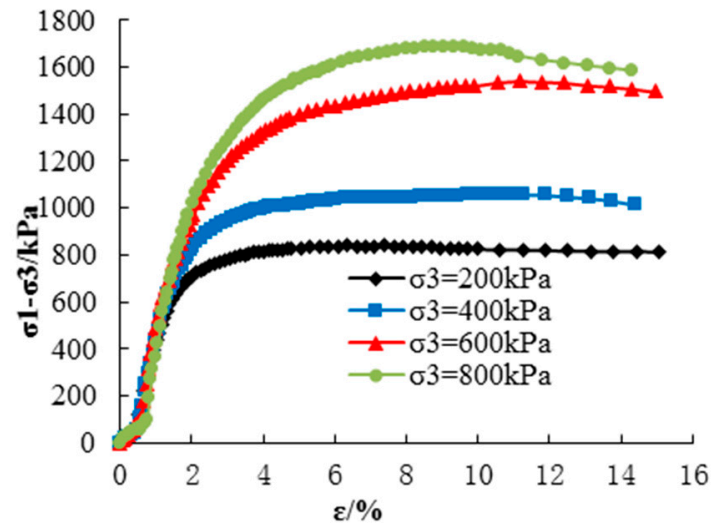

(b) $G F R=32 \%$

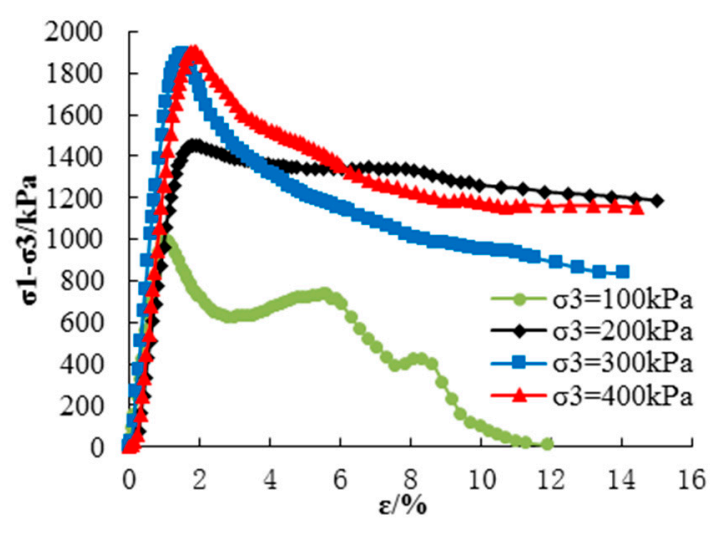

(d) $G F R=64 \%$

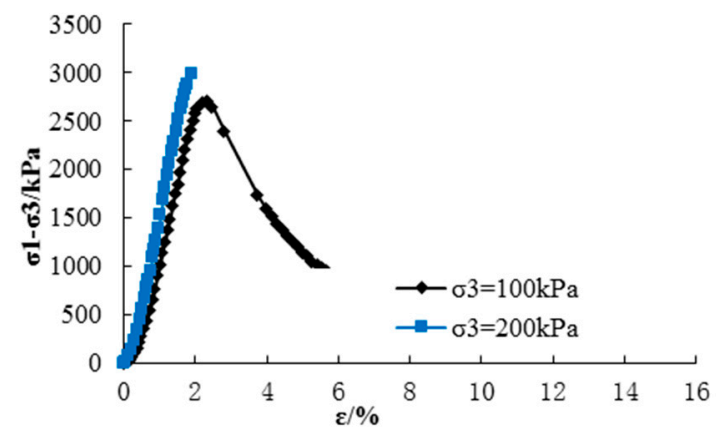

(e) $G F R=80 \%$

Figure 3. Deviatoric stress and axial strain curve in different grouting filling ratios at age $=7 \mathrm{~d}$.

\subsubsection{Strength Characteristics}

According to the Mohr-Coulomb criterion, the strength parameters (cohesion $c$ and internal friction angle $\varphi$ ) can be calculated from the above strength tests, which are listed in Table 2. At the same curing time, with the increase of GFR, the cohesion increased exponentially, and the internal friction angle increased generally and then kept stable, as shown in Figure 4. In particular, when the GFR reached $48 \%$, the cohesion increased to about $200 \mathrm{kPa}$ which was more than three times of that without grouting, and the internal friction angle reached up to the maximum which was more than $30^{\circ}$. Furthermore, the strength parameters increased in general with the increase of curing time. 
Table 2. Results of triaxial compression test.

\begin{tabular}{ccccc}
\hline Label & GFR (\%) & Curing Time (d) & $c(\mathbf{k P a})$ & $\boldsymbol{\varphi}\left({ }^{\circ}\right)$ \\
\hline G-0 & 0 & - & 60.4 & 1.9 \\
\hline G16-3 $^{*}$ & 16 & 3 & 142.5 & 5.1 \\
G32-3 & 32 & 3 & 178.8 & 23.1 \\
G48-3 & 48 & 3 & 199.7 & 30.0 \\
G64-3 & 64 & 3 & 400.1 & 27.9 \\
G16-7 & 16 & 7 & 149.6 & 7.3 \\
G32-7 & 32 & 7 & 160.9 & 25.7 \\
G48-7 & 48 & 7 & 213.5 & 31.0 \\
G64-7 & 64 & 7 & 404.3 & 30.3 \\
\hline
\end{tabular}

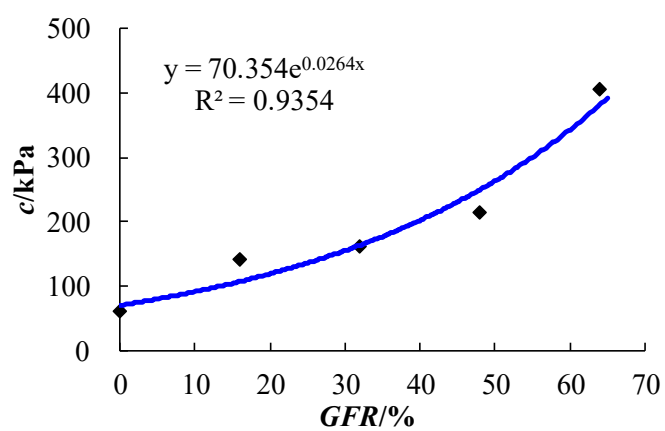

(a) Cohesion

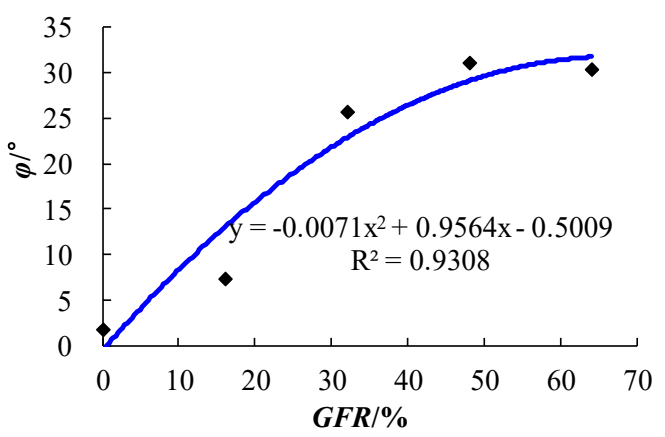

(b) Internal friction angle

Figure 4. Cohesion and internal friction angle results under different grouting filling ratios (GFRs) at 7 d curing time.

\subsubsection{Scanning Electron Microscopy (SEM) Characterization}

To analyze the mechanism of strength evolution characteristic after grouting, the scanning electron microscopy (SEM) analysis for different GFRs was carried out [27]. The test results are displayed in Figure 5.

For the sample with a small GFR, i.e., $16 \%$ and $32 \%$, the structure was loosened and contained many large pores, as shown in Figure 5a,b. In addition, few cement hydration products were formed in the sample, especially when GFR $=16 \%$, which indicated that the strength could be increased slightly. However, with the increase of GFR, numerous pores were filled by cement particles and the structure seems to be more dense, as shown in Figure $5 c$,d. In addition, a large amount of cement hydration products, i.e., calcium silicate hydrates (CSH) and ettringite crystals (AFt) were formed in the completely weathered granite, which can improve the strength of completely weathered granite significantly. 


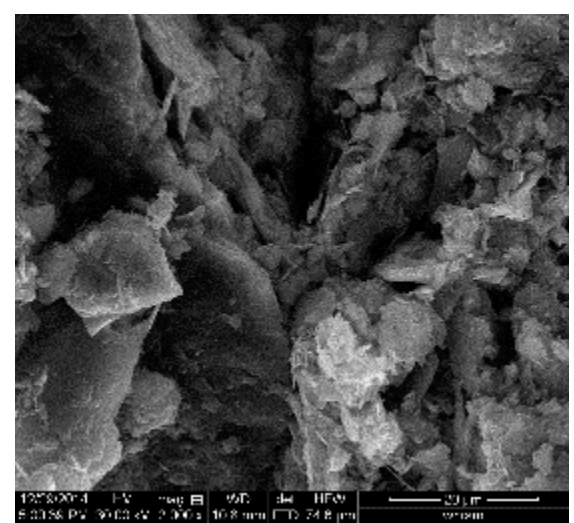

(a) $G F R=16 \%$

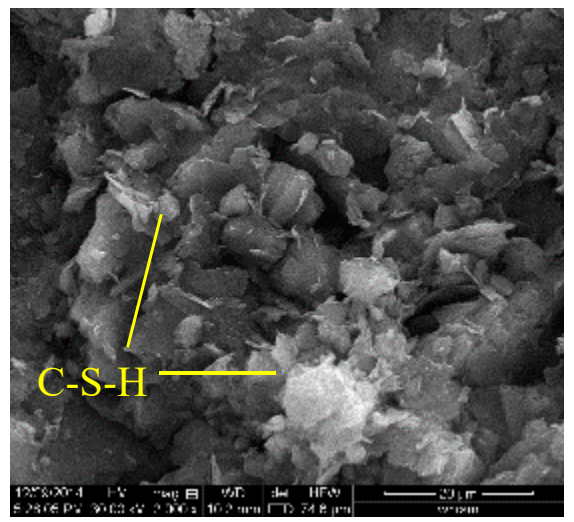

(c) $G F R=48 \%$

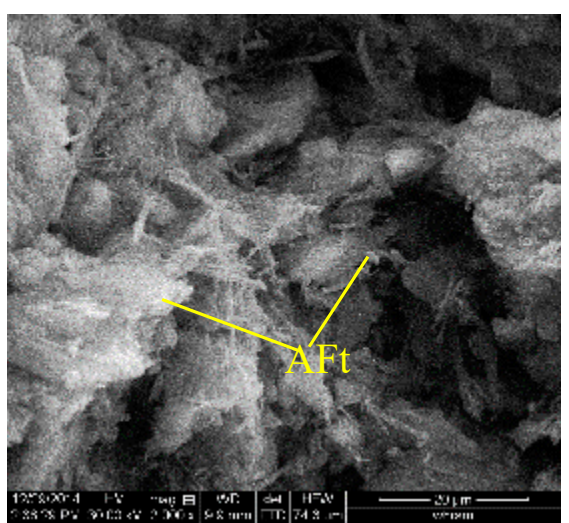

(b) $G F R=32 \%$

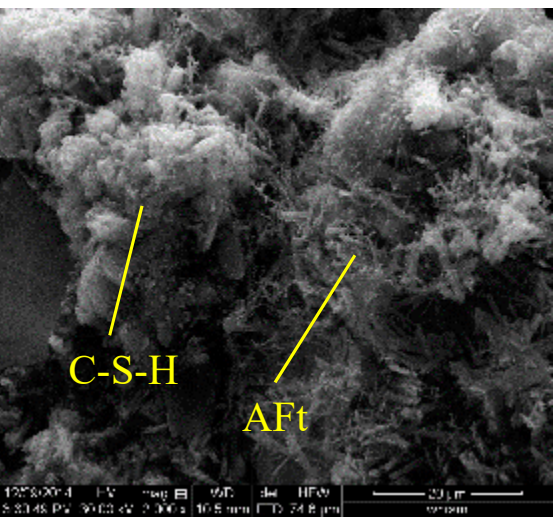

(d) $G F R=64 \%$

Figure 5. Scanning electron microscopy (SEM) results for different grouting filling ratio.

\subsection{Permeability Test}

Figure 6 shows the permeability coefficient results and indicates that the permeability coefficient under different GFR exhibited three evolution stages: Slowly decreasing stage, sharply decreasing stage and stable stage. For the sample without grouting, the permeability coefficient was $4.05 \times 10^{-5} \mathrm{~cm} / \mathrm{s}$. With the GFR increased to $16 \%$, the permeability coefficient decreased slowly to $8.6 \times 10^{-6} \mathrm{~cm} / \mathrm{s}$. In contrast, when GFR exceeded $32 \%$, the permeability coefficient decreased sharply from the order of $10^{-5} \mathrm{~cm} / \mathrm{s}$ to $10^{-8} \mathrm{~cm} / \mathrm{s}$. However, when GFR exceeded $48 \%$, the permeability coefficient changed by a few.

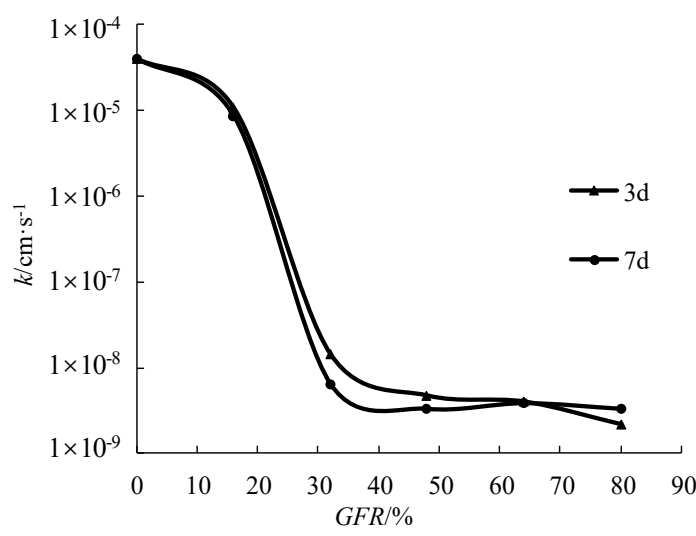

Figure 6. Permeability test results for different grouting filling ratios.

The main reasons that the permeability coefficient could be decreased with the increase of the GFR were analyzed as follows. First, from a physical perspective, the addition of grout could fill the 
pores of the sample, which can decrease the porosity, thereby reducing the connectivity of the pores and increasing the tortuosity of the seepage process, and finally, decreasing the internal permeability of the sample. Secondly, from the chemical perspective, the cement hydration products underwent a series of physical and chemical reactions with the particles and water to enhance the cementing ability, which reduced the permeability coefficient of the sample.

\subsection{Anti-Washout Test}

A comprehensive test method was used to investigate the anti-washout performance of completely weathered granite after grouting. The test results are shown in Table 3 and Figure 7.

Table 3. Anti-washout results.

\begin{tabular}{ccccccccc}
\hline \multirow{2}{*}{ No } & \multirow{v}{*}{$\left(\mathbf{m} \cdot \mathbf{s}^{-\mathbf{1}}\right)$} & \multirow{2}{*}{ Age } & \multicolumn{7}{c}{ PER/\% } \\
\cline { 3 - 8 } & & & GFR $=\mathbf{0} \%$ * & GFR $=\mathbf{1 6 \%}$ & GFR $=\mathbf{3 2} \%$ & GFR $=\mathbf{4 8} \%$ & GFR $=\mathbf{6 4} \%$ & GFR $=\mathbf{8 0} \%$ \\
\hline 1 & 0 & 3 & 97.8 & 56.2 & 31.5 & 9.8 & 3.5 & 1.5 \\
2 & 0 & 7 & - & 54.8 & 30.6 & 9.3 & 3.4 & 1.3 \\
3 & 0.2 & 3 & 100 & 100 & 52.4 & 42.7 & 39.7 & 32.8 \\
4 & 0.2 & 7 & - & 100 & 51.4 & 45.2 & 32.9 & 31.0 \\
5 & 0.4 & 3 & - & 100 & 68.8 & 53.1 & 51.0 & 45.6 \\
6 & 0.4 & 7 & - & 100 & 63.0 & 51.8 & 40.3 & 39.7 \\
7 & 0.6 & 3 & - & 100 & 72.2 & 59.5 & 55.0 & 48.8 \\
8 & 0.6 & $7 \mathrm{~d}$ & - & 100 & 75.7 & 58.7 & 53.4 & 42.0 \\
\hline
\end{tabular}

${ }^{*}$ For the test in GFR $=0 \%$, the results in different curing age were almost the same. The results in high velocity were significantly greater than with low velocity $(0.2 \mathrm{~m} / \mathrm{s})$, which indicates that the particle erosion ratio (PER) will be $100 \%$ for the other higher velocity.

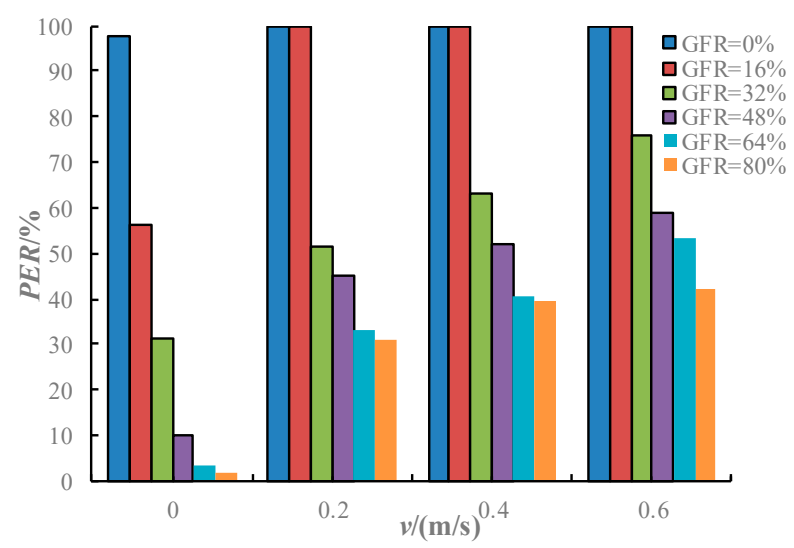

Figure 7. PER results under different water velocities at $7 \mathrm{~d}$ curing time.

It can be observed that the PER decreased significantly with the increasing GFR and decreasing water flow rate. Under the hydrostatic condition $(v=0 \mathrm{~m} / \mathrm{s})$, the PER decreased to below $10 \%$ when GFR $\geq 48 \%$, indicating that anti-washout performance could be satisfied after the GFR increased to more than $48 \%$. When the water velocity increased to $0.2 \mathrm{~m} / \mathrm{s}$, the PER of most of the samples was lower than $50 \%$, with the minimum being lower than $35 \%$. This indicates that the anti-washout performance and PER could be significantly modified by adjusting the grouting volume when the velocity was small. However, with the water velocity further increased to more than $0.4 \mathrm{~m} / \mathrm{s}$, the PER of most of the samples exceeded $50 \%$. This indicates that the anti-washout performance cannot be significantly modified by merely increasing grouting volume when the velocity was very high. During this condition, the modified cement slurries or chemical slurries with favorable anti-washout performance were suggested to decrease the velocity primarily, then the Portland cement with the suggested GFR could be used to reinforce the ground.

In general, the higher filling ratios govern the better grouting reinforce effect. However, considering the economic cost and construction efficiency, an appropriate grouting volume should be proposed. 
Based on the above analysis of strength, permeability and anti-washout performance, it can be obtained that in completely weathered granite, GFR $=48-64 \%$ is the suitable grouting parameter range. The result is similar in the medium and coarse sand grouting (namely GFR $=50-70 \%$ ), but is significantly different in the gravel sand grouting (namely GFR $=70-100 \%$ ) according to the permeation grouting theory, as presented by Cui and Cui [27]. However, it should be noted that grouting in completely weathered granite is significantly different with that in sandy soil, especially in terms of the grouting diffusion mechanism. The results from permeation grouting theory cannot be used in regards to the completely weathered granite. In addition, Cui and Cui [27] summarized the grouting filling ratio of $30-50 \%$ for clay soil from the field investigation. This indicates that the grouting filling ratio for different ground materials may differ and, thus, they should be determined according to the details of the hydrogeological condition.

\section{Field Investigation of Grouting Reinforcement Effect-A Case Study}

The Junchang tunnel is a part of a major project at Cenxi highway in Guangxi province, China. Due to the unfavorable geological conditions, the tunnel suffered serious water and mud inrush disasters, and curtain grouting was thus adopted to overcome the difficulties. To verify the effectiveness of the developed grouting volume, field investigations of curtain grouting were conducted in the Junchang tunnel.

\subsection{Ground Conditions and Geological Disasters}

The ground conditions were evaluated according to the geological prospecting and geophysical prospecting, as illustrated in Figure 8. The lithology throughout the tunnel was weathered granite with different grades. In particular, from $C K 7+838.5$ to $C K 7+981.6$, the area is a large rich-water, with completely weathered granite region, which is makes for a high-risk region. Tunnel construction in these regions has suffered four large-scale waters and mud inrush disasters from 11 September 2013 to 23 October 2015, as shown in Figure 9. The largest water inflow volume exceeded 250,000 $\mathrm{m}^{3}$, which resulted in the severe property damage and hindered the construction seriously [13].

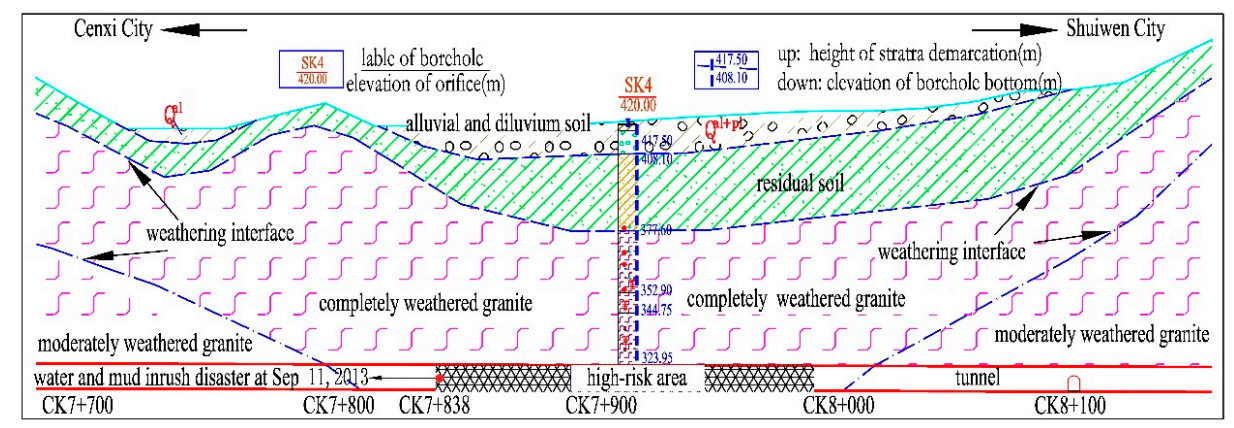

Figure 8. Geological profile of the Junchang tunnel.

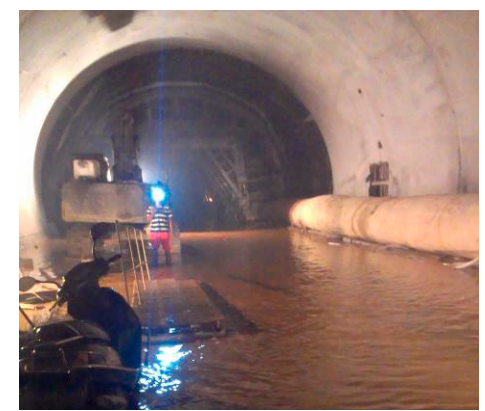

(a) Water inrush in $\mathrm{CK} 7+838$

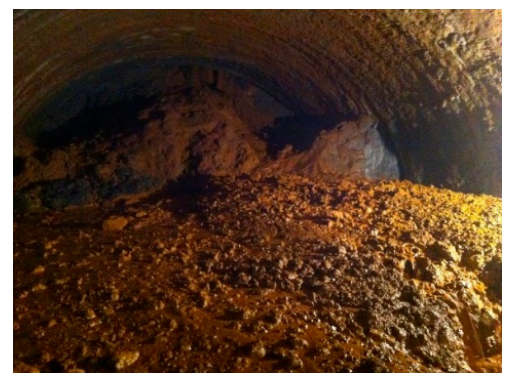

(b) Mud inrush in DK7+963

Figure 9. Water and mud inrush accidents in the Junchang tunnel. 


\subsection{Grouting Design}

The main grouting parameters in the Junchang tunnel were designed according to the following specifications:

(1) As shown in Figures 10 and 11, 95 grouting holes including 7 cycles (A-G) from outside to inside were designed. In addition, the construction process for the curtain grouting was conducted from cycle A to cycle G.

(2) The designed grouting volume was $48 \mathrm{~m}^{3} / \mathrm{m}$ according to the above tests.

(3) The curtain grouting thickness of 5-8 $\mathrm{m}$ was adopted based on the numerical results [13]. The grouting reinforced length was $15 \mathrm{~m}, 20 \mathrm{~m}$, or $25 \mathrm{~m}$, depending on the geological conditions.

(4) Considering that the grouting spread pattern in completely weathered granite was mainly fractured grouting, the grouting pressure was required to reach the initiation pressure of the ground. In addition, the buried depth of this high-risk zone is approximately $96 \mathrm{~m}$. Thus, the designed maximum grouting pressure was 4-6 MPa.

(5) Considering the factors of anti-washout performance, strength performance and economics, several grouting materials including the cement slurry, cement-sodium silicate slurry and cement-GT slurry were adopted to use in different hydraulic conditions [13].

(6) The grouting effect was examined by examination holes, $P-Q-t$ curve, and excavation $[16,28]$.

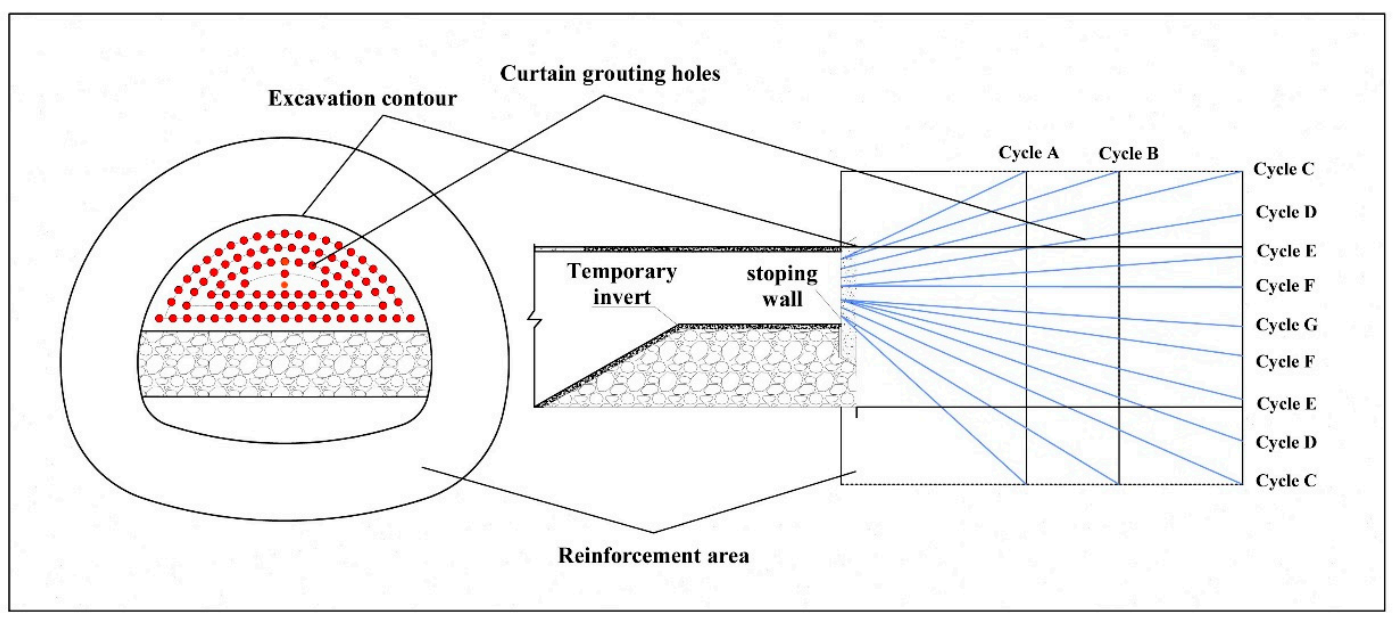

Figure 10. Curtain grouting design.

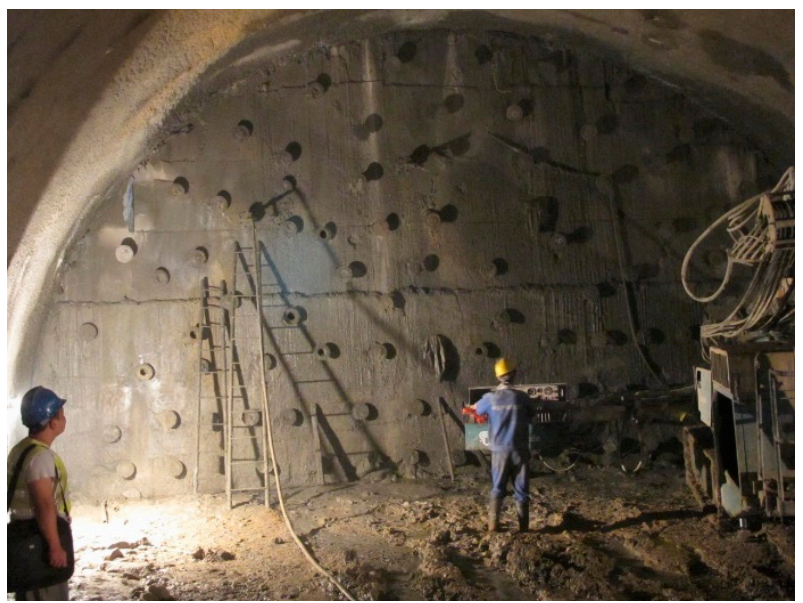

Figure 11. Construction of curtain grouting in DK7+952. 


\subsection{Grouting Effects Examination}

In order to evaluate the grouting reinforcement effect, the grouting cycle zone (DK7+952 DK7+932) was taken as an example. In this grouting cycle, seven examination holes were designed to investigate the hydraulic and mechanical behavior of the ground after a curtain grouting, which are shown in Table 4 and Figure 12. The detailed information exposed by examination holes is shown in Table 5.

Table 4. Design parameters of examination holes.

\begin{tabular}{|c|c|c|c|c|c|c|c|}
\hline \multirow{2}{*}{ Label } & \multicolumn{2}{|c|}{ Coordinate of Opening Hole } & \multicolumn{2}{|c|}{ Coordinate of Final Hole } & \multirow{2}{*}{$\begin{array}{c}\text { Declination } \\
\left({ }^{\circ}\right)\end{array}$} & \multirow{2}{*}{$\begin{array}{c}\text { Vertical Angle } \\
\left({ }^{\circ}\right)\end{array}$} & \multirow{2}{*}{$\begin{array}{c}\text { Depth of Drilling } \\
\text { Hole (m) }\end{array}$} \\
\hline & $X_{0}(\mathrm{~cm})$ & $\mathrm{Y}_{0}(\mathrm{~cm})$ & $X(\mathrm{~cm})$ & $Y(\mathrm{~cm})$ & & & \\
\hline $\mathrm{J}-1$ & 0 & 0 & 78 & 453 & 2.2 & 12.8 & 20.5 \\
\hline $\mathrm{J}-3$ & 130 & -405 & 384 & -676 & 7.2 & -7.7 & 20.3 \\
\hline $\mathrm{J}-4$ & -377 & -392 & -707 & -676 & -9.4 & -8.1 & 20.5 \\
\hline $\mathrm{J}-5$ & -560 & -676 & -1186 & -254 & -17.4 & 11.9 & 21.4 \\
\hline
\end{tabular}

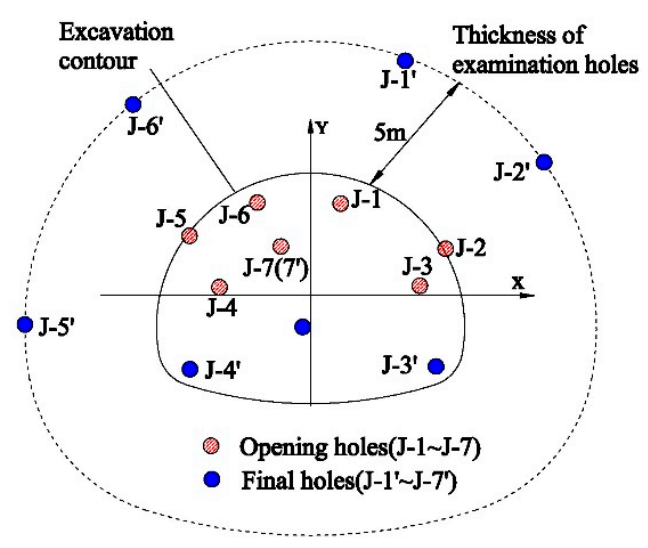

Figure 12. Layout of examination holes.

Table 5. Results of the examination holes.

\begin{tabular}{cccccc}
\hline Label & $\begin{array}{c}\text { Depth of } \\
\text { Drilling }(\mathbf{m})\end{array}$ & $\begin{array}{c}\text { Depth of } \\
\text { Hole-Making } \mathbf{( m )} \mathbf{~}^{\mathbf{1}}\end{array}$ & $\begin{array}{c}\text { Hole-Making } \\
\text { Rate (\%) }\end{array}$ & $\begin{array}{c}\text { Water Inflow } \\
\mathbf{( L / m i n )}\end{array}$ & $\begin{array}{c}\text { Location of Water } \\
\text { Inflow }(\mathbf{m})\end{array}$ \\
\hline J-1 & 18.5 & 17.0 & 92 & 1.2 & 17 \\
J-2 & 17.8 & 17.5 & 98 & 4.1 & 17 \\
J-3 & 19.0 & 18.0 & 95 & 4.6 & 16 \\
J-4 & 18.0 & 17.6 & 98 & 4.4 & 16 \\
J-5 & 18.5 & 18.0 & 97 & 4.5 & 15 \\
J-6 & 18.0 & 17.0 & 94 & 1.7 & 16 \\
J-7 & 18.0 & 17.5 & 97 & 3.6 & 16 \\
\hline
\end{tabular}

Notes: 1. Depth of hole-making is length where no significant collapse occur, namely the stability drilling length. 2. The hole-making rate is defined as the ratio of the hole-making depth divided by drilling depth

It can be seen from the Table 5 that the hole-making rates after grouting were all more than $90 \%$, which indicated that there was no serious collapse in the holes and the ground had been reinforced well. Furthermore, Table 5 shows that water inflows were less than $5 \mathrm{~L} / \mathrm{min}$, and the minimum water inflow was merely $1.2 \mathrm{~L} / \mathrm{min}$, as shown in Figure 13a. According to the field investigation, the water inflows exposed before grouting were about $50 \mathrm{~L} / \mathrm{min}$, as shown in Figure 13b. This indicates that the water inflows have decreased by more than $90 \%$ after grouting. In addition, the initial $15 \mathrm{~m}$ for the examination holes were dry, and it was merely at the last few meters that some water appeared. This means that the water has been driven away and the surrounding rock has possessed favorable water plugging behavior. 


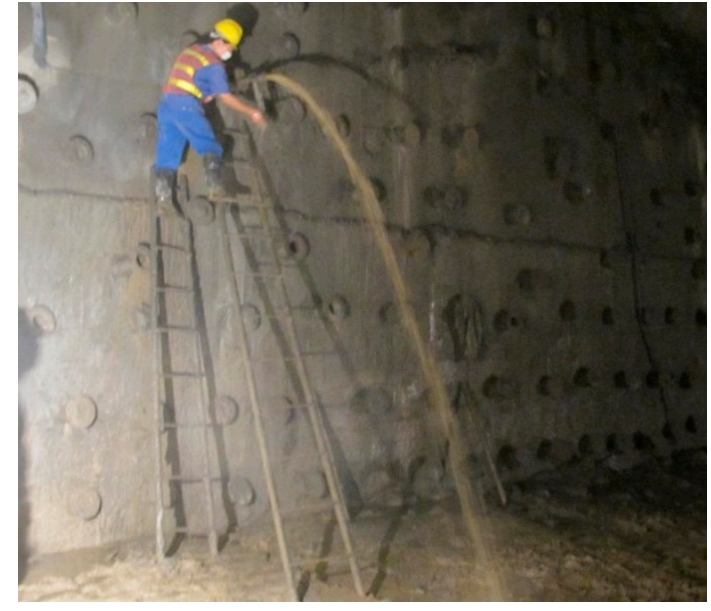

(a) Pre-grouting

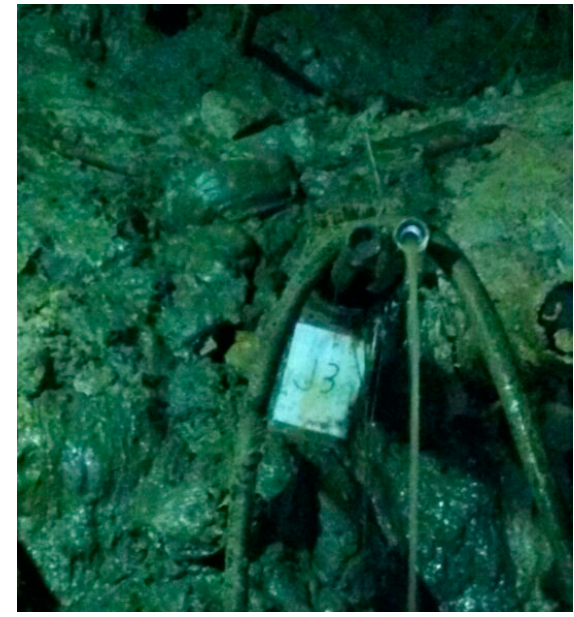

(b) Post-grouting

Figure 13. Water inflow pre- and post-grouting in DK7+952.

In order to evaluate the strength, compactness and the geosphere integrity of the ground, the grouting tests in the examination holes were carried out. The key parameters in grouting tests, namely $P$ (injection pressure)- $Q$ (injection velocity)-t (time) curves were recorded. Figure 14 shows the typical $P$-Q- $t$ curves of J-2.

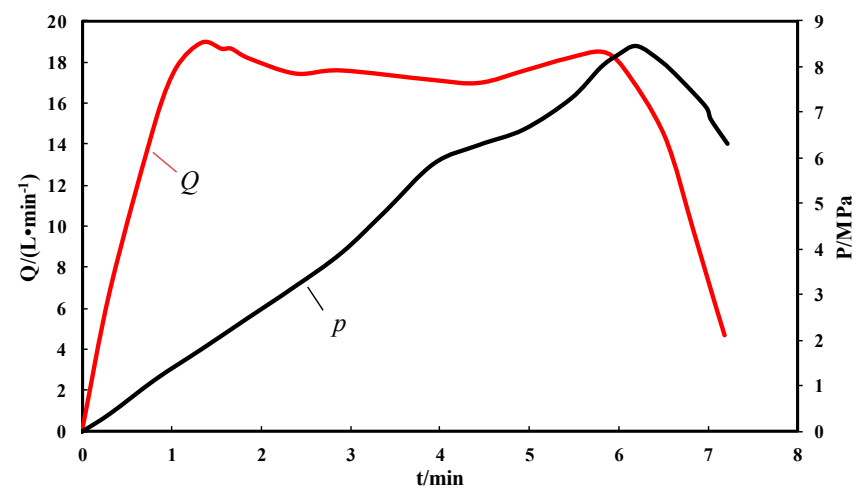

Figure 14. $P-Q-\mathrm{t}$ curves.

For grouting in completely weathered granite, the ground was generally reinforced by composed grouting patterns, including the filling, permeating, compaction and splitting grouting. First, the grout was injected by way of filling and permeating, and the grouting pressure was relatively low due to the high porosity of ground. Therefore, a great deal of grout was demanded to fill the pores or fractures, showing the high injection velocity in this stage. Then, when the pores or fractures were entirely filled, the higher grouting pressure was demanded to surmount the minimum principal stress of the ground [16]. At this stage, the grouting patterns were mainly compaction and splitting grouting, and the grouting pressure increased significantly, and the grouting velocity decreased sharply.

Figure 14 displays that the grouting pressure quickly increased to $8 \mathrm{MPa}$, and the grouting velocity sharply declined to $5 \mathrm{~L} / \mathrm{min}$ in 6 min indicating that unfavorable geology was reinforced by the grouting. This can be explained as follows: The pores or fractures in the ground has been filled, and the ground compactness and strength were improved significantly during the curtain grouting, so that the grouting pressure increased rapidly and the grout could not be pumped largely into the ground.

Based on the above investigation, the hydraulic and mechanical performance of the ground was improved notably and satisfied by the excavation environment. As shown in Figure 15, the tunnel face was dry and the medium was reinforced by lots of grout veins. The excavation demonstrated that the grouting parameters proposed above were reliable. 


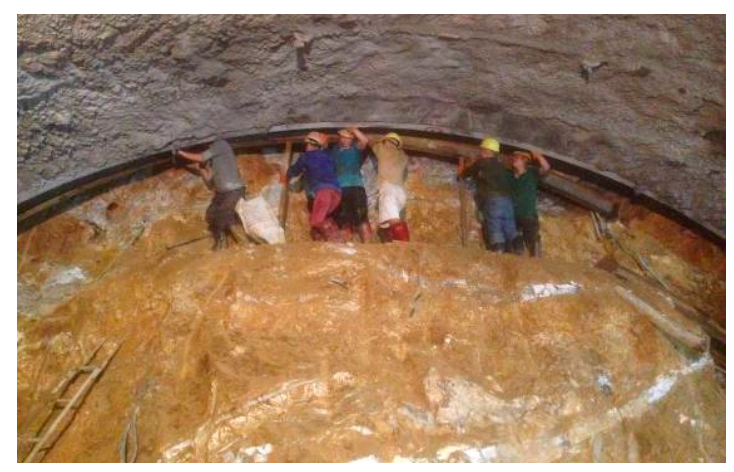

Figure 15. Grouting effect exposed by excavation in DK7+948.

\section{Conclusions}

In order to propose the suitable grouting parameters for field engineering, considering the factors of grouting volume (GFR), curing age and water velocity, numerous tests including strength, permeability and anti-washout were conducted to evaluate the grouting reinforcement effect of completely weathered granite. The main conclusions drawn are as follows:

(1) The completely weathered granite could be effectively reinforced by grouting. In addition, with the increase of grouting filling ratio and curing time, the physical and mechanical properties can be improved significantly. In particular, when the GFR increased to $48 \%$, the cohesion and internal friction angle increased to about $200 \mathrm{kPa}$ and $30^{\circ}$, which were more than three and ten times of that without grouting. Simultaneously, the permeability coefficient decreased two orders of magnitude, namely from $4.05 \times 10^{-5} \mathrm{~cm} / \mathrm{s}$ to $1 \times 10^{-7} \mathrm{~cm} / \mathrm{s}$, and the PER decreased sharply to below $10 \%$ in the lower water flow rate. The results demonstrate that the completely weathered granite was reinforced well after the grouting with GFR $\geq 48 \%$.

(2) In the high-water velocity condition, the grouting effect decreased sharply. In particular, when the velocity increased to more than $0.4 \mathrm{~m} / \mathrm{s}$, the anti-washout performance after grouting with Portland cement was extremely deficient, which the PER exceeded $50 \%$. The results indicate that in the high-water velocity condition, the composite slurries or measurements should be taken, i.e., the chemical slurry was primarily used to control the water velocity, and the Portland cement was then used to reinforce the ground.

(3) According to the experimental studies, the GFR of $48 \%$ was proposed as an appropriate grouting parameter in completely weathered granite. This suggested value was demonstrated to be reasonable, effective and reliable by field investigations in the Junchang tunnel.

Author Contributions: Conceptualization, J.L.; Methodology, W.Z. and J.L.; Formal Analysis, D.W., K.L. and G.L.; Investigation, W.Z., D.W., K.L. and L.Q.; Data Curation, J.L. and G.L.; Writing-Original Draft Preparation, W.Z., J.L. and G.L..; Writing-Review \& Editing, J.L., G.L. and K.L..; Supervision, J.L.; Project Administration, J.L.; Funding Acquisition, J.L.

Funding: This research was funded by the National Natural Science Foundation of China [grant number 51809253], and the Natural Science Foundation of Fujian Province, China [grant number 2019J01142].

Conflicts of Interest: The authors declare that they have no conflicts of interest.

Data Availability: The data used to support the findings of this study are available from the corresponding author upon request.

\section{References}

1. Zhao, Y.; Li, P.; Tian, S. Prevention and treatment technologies of railway tunnel water inrush and mud gushing in China. J. Rock Mech. Geotech. Eng. 2013, 5, 468-477. [CrossRef]

2. Liu, J.; Chen, W.; Yang, D.; Yuan, J.; Li, X.; Zhang, Q. Nonlinear seepage-erosion coupled water inrush model for completely weathered granite. Mar. Georesour. Geotechnol. 2018, 36, 484-493. [CrossRef] 
3. Liu, J.; Chen, W.; Liu, T.; Yu, J.; Dong, J.; Nie, W. Effects of Initial Porosity and Water Pressure on Seepage-Erosion Properties of Water Inrush in Completely Weathered Granite. Geofluids 2018, 2018. [CrossRef]

4. Davis, G.M.; Horswill, P. Groundwater control and stability in an excavation in Magnesian Limestone near Sunderland, NE England. Eng. Geol. 2002, 66, 1-18. [CrossRef]

5. Sadeghiyeh, S.M.; Hashemi, M.; Ajalloeian, R. Comparison of permeability and groutability of ostur dam site rock mass for grout curtain design. Rock Mech. Rock Eng. 2013, 46, 341-357. [CrossRef]

6. Høien, A.H.; Nilsen, B. Rock mass grouting in the Løren tunnel: Case study with the main focus on the groutability and feasibility of drill parameter interpretation. Rock Mech. Rock Eng. 2014, 47, 967-983. [CrossRef]

7. Barani, H.R.R.; Khatib, M.M. Back analysis of grout treatment at Sumbar Dam using the joint hydraulic factor. Rock Mech. Rock Eng. 2015, 48, 2485-2488. [CrossRef]

8. Liu, J.; Chen, W.; Nie, W.; Yuan, J.; Dong, J. Experimental research on the mass transfer and flow properties of water inrush in completely weathered granite under different particle size distributions. Rock Mech. Rock Eng. 2019, 52, 2141-2153. [CrossRef]

9. Liu, J.; Li, X.; Saffari, P.; Liang, Q.; Li, L.; Chen, W. Developing a Polypropylene Fabric, Silica Fume, and Redispersible Emulsion Powder Cementitious Composite for Dynamic Water Environment. Polymers 2019, 11, 47. [CrossRef]

10. Foyo, A.; Tomillo, C.; Maycotte, J.I.; Willis, P. Geological features, permeability and groutability characteristics of the Zimapan Dam foundation, Hidalgo State, Mexico. Eng. Geol. 1997, 46, 157-174. [CrossRef]

11. Li, X.F.; Sun, J.T.; Chen, W.Z.; Yuan, J.Q.; Liu, J.Q.; Zhang, Q.Y. Strength and anti-washout property of fibre silica fume cement grout. Rock Soil Mech. 2018, 39, 3157-3164.

12. Zhong, D.H.; Yan, F.G.; Li, M.C.; Huang, C.X.; Fan, K.; Tang, J.F. A real-time analysis and feedback system for quality control of Dam foundation grouting engineering. Rock Mech. Rock Eng. 2015, 48, 1947-1968. [CrossRef]

13. Liu, J.; Chen, W.; Yuan, J.; Li, C.; Zhang, Q.; Li, X. Groundwater control and curtain grouting for tunnel construction in completely weathered granite. Bull. Eng. Geol. Environ. 2018, 77, 515-531. [CrossRef]

14. Akbulut, S.; Saglamer, A. Estimating the groutability of granular soils: A new approach. Tunn. Undergr. Space Technol. Inc. Trenchless Technol. Res. 2002, 17, 371-380. [CrossRef]

15. Azimian, A.; Ajalloeian, R. Permeability and groutability appraisal of the Nargesi Dam site in Iran based on the secondary permeability index, joint hydraulic aperture and lugeon tests. Bull. Eng. Geol. Environ. 2015, 74, 845-859. [CrossRef]

16. Zhang, D.L.; Fang, Q.; Lou, H.C. Grouting techniques for the unfavorable geological conditions of Xiang'an subsea tunnel in China. J. Rock Mech. Geotech. Eng. 2014, 6, 438-446. [CrossRef]

17. Bruce, D.A.; Shirlaw, J.N. Grouting of Completely Weathered Granite with Special Reference to the Construction of the Hong Kong Mass Transit Railway. Available online: www.geosystemsbruce.com/v20/ biblio/1985_groutingWeatheredGranite.pdf (accessed on 1 July 2019).

18. Li, S.C.; Liu, R.T.; Zhang, Q.S.; Zhang, X. Protection against water or mud inrush in tunnels by grouting: A review. J. Rock Mech. Geotech. Eng. 2016, 8, 753-766. [CrossRef]

19. Engineers, U.A. Grouting Methods and Equipment. Unified Facilities Criteria (UFC 3-220-06). Available online: https://www.wbdg.org/ffc/dod/unified-facilities-criteria-ufc/ufc-3-220-06 (accessed on 1 July 2019).

20. Lombardi, G.; Deere, D. Grouting design and control using the GIN principle. Int. Water Power Dam Construct. 1993, 45, 15-22.

21. Rafi, J.Y.; Stille, H. Applicability of using GIN method, by considering theoretical approach of grouting design. Geotech. Geol. Eng. 2015, 33, 1431-1448. [CrossRef]

22. Stille, B.; Stille, H.; Gustafson, G.; Kobayashi, S. Experience with the real time grouting control method. Geomech. Tunn. 2009, 2, 447-459.

23. Stille, H.; Gustafson, G.; Hassler, L. Application of new theories and technology for grouting of dams and foundations on rock. Geotech. Geol. Eng. 2012, 30, 603-624. [CrossRef]

24. Nonveiller. Grouting Theory and Practice; Elsevier Science Publishers: New York, NY, USA, 1989.

25. Zhang, M.Q.; Peng, F. Grouting Technology in Underground Engineering; Geological Publishing House: Beijing, China, 2008. 
26. Cui, J.J.; Cui, X.Q. Grouting Technology in Tunneling and Underground Engineering; China Architectural Press: Beijing, China, 2011.

27. Liu, J.; Chen, W.; Yuan, J. Test on anti-scouring property of grouting reinforced body in completely weathered granite. Chin. J. Rock Mech. Eng. 2016, 35, 1767-1775.

28. Wang, Q.; Qu, L.Q.; Guo, H.Y.; Wang, Q.S. Grouting reinforcement technique of Qingdao Jiaozhou Bay subsea tunnel. Chin. J. Rock Mech. Eng. 2011, 30, 790-802. 